\title{
CAFFEINE CONSUMPTION HABITS AND PERCEPTION OF ADOLESCENTS IN CHENNAI POPULATION*
}

\author{
PRIADARSINI T*, GAYATRIDEVI R
}

Department of Physiology, Saveetha Dental College and Hospitals, Saveetha University, Chennai, Tamil Nadu, India. Email: dachupria.rsk@gmail.com

Received: 16 July 2016, Revised and Accepted: 31 August 2016

\section{ABSTRACT}

Objective: Caffeine consumption by adolescent population has increased dramatically over the last decade through increased coffee consumption and energy drinks. However, caffeine causes many adverse effects, which demands people's attention. The purpose of this study was to determine the most popular caffeinated product among adolescents and the knowledge and belief of adolescents about caffeine in their day to day life.

Methods: An online survey was created and about 260 responses were obtained. Only 248 were counted as the remaining was removed by exclusion criteria.

Results: The most popular caffeine intake by adolescents was coffee. Students ingested caffeine at levels that could cause negative health effects and seemed unaware of the total amount of caffeine consumed.

Conclusion: More information about caffeine should be incorporated into health education at all levels, so students can identify and avoid negative effects along with caffeine withdrawal and addiction.

Keywords: Caffeine, Coffee, Adolescents, Addiction, Habits.

(C) 2016 The Authors. Published by Innovare Academic Sciences Pvt Ltd. This is an open access article under the CC BY license (http://creativecommons. org/licenses/by/4. 0/) DOI: http://dx.doi.org/10.22159/ajpcr.2016.v9s3.14147

\section{INTRODUCTION}

"Caffeine is the most commonly used the mood-altering drug in the world." [1] Caffeine is a central nervous system stimulant of the methylxanthine class [2]. It is the world's most widely consumed psychoactive drug, but unlike many other psychoactive substances, it is legal and unregulated in nearly all parts of the world. Caffeine is present in a wide range of products, namely, coffee, tea, soft drinks, hot chocolates, and confectionery such as chocolates and over-the-counter medications including cold remedies and analgesics. The concentration of caffeine differs between each product, and furthermore, the caffeine content with each product can also vary due to combination of factors. It is important to recognize that caffeine content is extremely variable within manufacturing and brewing techniques [3]. The earliest credible evidence of either coffee drinking or knowledge of the coffee tree appears in the middle of the $15^{\text {th }}$ century, in the Sufi monasteries of the Yemen in southern Arabia [4].

From Mocha, coffee spread to Egypt and North Africa, and by the $16^{\text {th }}$ century, it had reached the rest of the Middle East, Persia and Turkey. From the Middle East, coffee drinking spread to Italy, then to the rest of Europe, and coffee plants were transported by the Dutch to the East Indies and the Americas [5]. Baba Budan lived in the $17^{\text {th }}$ century in India. On the way back from his pilgrimage, he encountered a strange drink that the Arabs living there made which was none other than coffee. This contributed to the spread of coffee in India.

Adolescence is viewed as a dynamic and complex transitional time in life. During this time, every aspect of the adolescent's development and social growth is going through a transformation [6]. Even with the importance put on nutrition, adolescents have poor nutritional habits [7]. Healthy eating is associated with eating vegetables without butter, regulating fat intake, calorie intake, limiting caffeine, and avoid eating "bunch of junk" [8]. Soft drinks offer a wide array of less-thandesirable ingredients. One of the ingredients scrutinized over the last several decades is caffeine. Caffeine causes decreased performance in the classroom, sleep deprivation, and viewing the addictive properties and acceptance of caffeine as a gateway drug $[6,9]$.

Caffeine is classified by the Food and Drug Administration as "generally recognized as safe." Toxic doses, over $10 \mathrm{~g} /$ day for an adult, are much higher than typical dose of under $500 \mathrm{mg}$ /day. However, pure powdered caffeine, which is available as a dietary supplement, can be lethal in tablespoon-sized amounts.

Global consumption of caffeine has been estimated at 120,000 tons/year, making it the world's most popular psychoactive substance. This amounts to one serving of a caffeinated beverage for every person every day [10].

This article will focus on the caffeine consumption habits and perception of the adolescent population in Chennai district of Tamil Nadu, India.

\section{METHODS}

A cross-sectional questionnaire survey was carried out to assess the knowledge and consumption of caffeinated products. A specially designed questionnaire consisting of 15 close-ended questions was said to assess the knowledge and efficient use of caffeinated products among the adult population in Chennai, Tamil Nadu, India. The questionnaire was made as an online survey, and the link was sent to the participants. The identity of the participants was maintained anonymous.

\section{RESULTS}

As it was an online survey, the link was sent to interested adults who willingly cooperated. There were about 260 responses, of which, 12 of the answers were excluded due to the exclusion criteria. Therefore, the total responses were 248 in number.

Coffee is the most favored caffeinated product preferred by $30.7 \%$ of the respondents, followed by energy drinks $25 \%$, tea $19.4 \%$, soft drinks $14.1 \%$, and others including confectionaries $10.8 \%$ (Fig. 1). 
Furthermore, for the frequency of consumption of caffeinated products, many participants have stated that they have a habit of including caffeinated products in their day to day diet (46.8\%). Other options were 2 days once $21.8 \%$, weekly once $17.7 \%$, and not specific $13.7 \%$ (Fig. 2 ).

The most popular caffeine intake was fruit flavored juices with $48.8 \%$ preference by participants followed by cola $31.2 \%$ and biscuits $20 \%$.

\section{DISCUSSION}

In this study, the purchase preference of caffeinated products has got maximum responses on homemade which included coffee ground and tea bags $(45.5 \%)$, followed by buying in restaurants $(25 \%)$, premade and store brought (16.5\%), and buying all of these (13\%).

For the awareness on quantity of caffeine on each product, $27.8 \%$ of respondents have stated that they know the quantity for each and every product they consume, and $34.7 \%$ have replied that they know somewhat about the quantity of caffeine. $17.7 \%$ of the participants are unsure about it and $19.8 \%$ have stated that they do not know the quantity of caffeine in the product they consume.

About $40.7 \%$ of the participants consider "Brand name" as a feature for buying caffeinated product, whereas "popularity among friends" is the nex with $26.6 \%$ followed by availability in shops $16.2 \%$ and cost $16.5 \%$ (Fig. 3)

According to the participants' choice, taste of the product (31\%) matters more while buying caffeinated products along with freshness of the product $(28.2 \%)$, health benefits $(21.8 \%)$, and quality of the product (19\%). Many participants have stated that the purpose of consuming caffeinated products is to stay awake (36.3\%), for headache $(19.8 \%)$, to satisfy craving $(14.5 \%)$, and other with no specific reason $(29.4 \%)$.

On skipping the consumption of caffeinated products for a day, there was no change or effect in about $50.8 \%$ participants. However, respondents have reported of restlessness in $19.8 \%$, headache in $13.3 \%$, and hyperactivity in $16.1 \%$ (Fig. 4).

About $71.8 \%$ of the respondents have reported caffeine to be a food supplement, whereas remaining $28.2 \%$ have reported it to be a drug

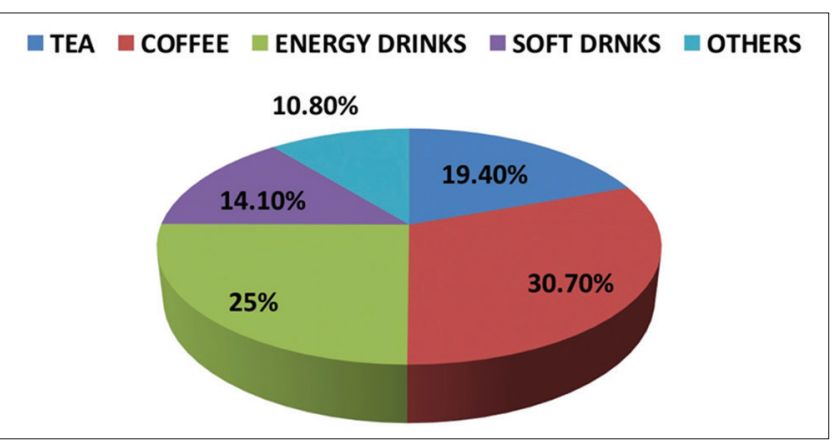

Fig. 1: Consumption of caffeinated products

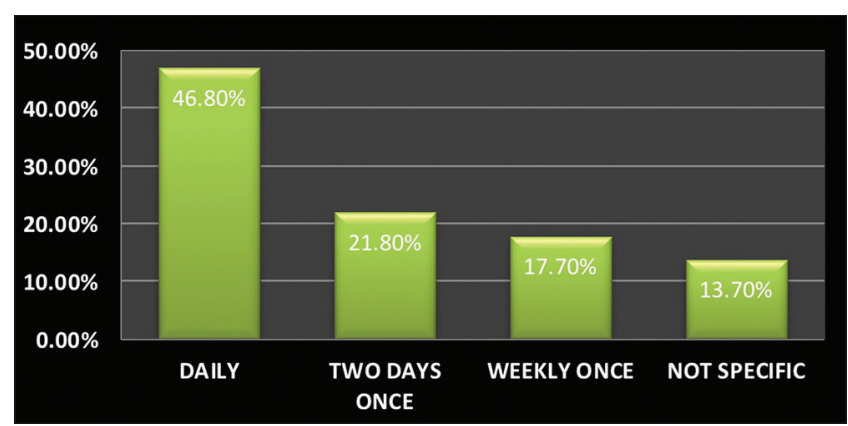

Fig 2: Frequency of caffeine consumption
(Fig. 5). Moderate doses 200-300 mg/day of caffeine for adults are not harmful but doses more than $500-600 \mathrm{mg} /$ day can cause side effects [11]

Caffeine ingested in lower doses has been shown to have positive effects [7]. Brice and Smith (2002) found that doses of caffeine (either $65 \mathrm{mg}$ taken 4 times over a $5 \mathrm{hrs}$ period or a larger dose of $200 \mathrm{mg}$ taken at once) taken over time or all at once had a positive effect on alertness, improved performance on simple and choice reactive tasks, improved performance on a cognitive vigilance task and a task requiring sustained response, and dual tracking/target detection. They also found that both doses increased anxiety [12].

About $41.1 \%$ of the participants have agreed that they are addicted to caffeine leaving out the remaining 58.9\% who are not addicted (Fig. 6).

Most short-term disadvantages to drinking caffeine are classified as withdrawal symptoms, as caffeine is considered a drug. According to an article published in the National Geographic, a day or so without caffeine can cause headaches, irritability, a lack of energy, and sleepiness. Ireland's Stimulant Drinks Committee report advised that consumption of highly caffeinated beverages should be discouraged in children to prevent possible increases in anxiety or nervousness (Reid) [13]. According to the study done by Mayo Clinic, people may experience different reactions to caffeine depending on regular caffeine consumption, body mass, age, medication use, and health conditions such as anxiety disorders. Their research also suggests that men are more susceptible to harmful effects of caffeine than women. Caffeine can also have a major impact on sleeping habits [14].

In contrast to many perceived disadvantages of consuming caffeine, there are also many advantages, which may explain why so many people consume the drug on a daily basis. For most healthy adults, consuming moderate doses of caffeine, or about 200-300 mg a day, equal to about two to four cups of brewed coffee, is not harmful. As a mental stimulant, caffeine increases alertness, cognition, and reaction speed. Caffeine reduces fatigue, therefore, improving performance on tasks such as driving, homework, and playing sports (Reid) [13].

Caffeine is being studied further for its potential benefits in battling Parkinson's disease, Alzheimer's, and cancer (Brain et al., 2000) [15]. Recent studies link coffee consumption to a range of good health effects, including decreased risk of dementia and decreased the risk of depression among women (Aubrey, 2013) [16]. Studies have also

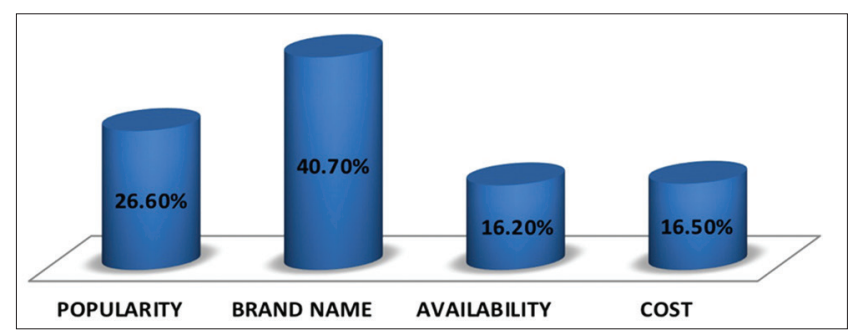

Fig. 3: Features considered for buying caffeinated products

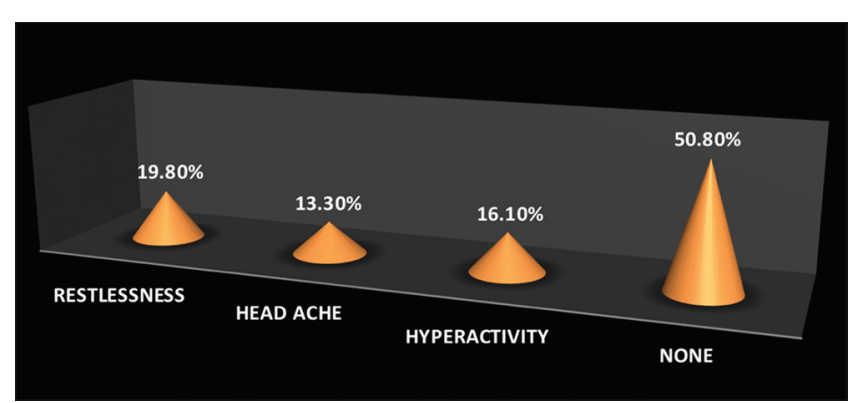

Fig. 4: Symptoms faced after caffeine consumption 


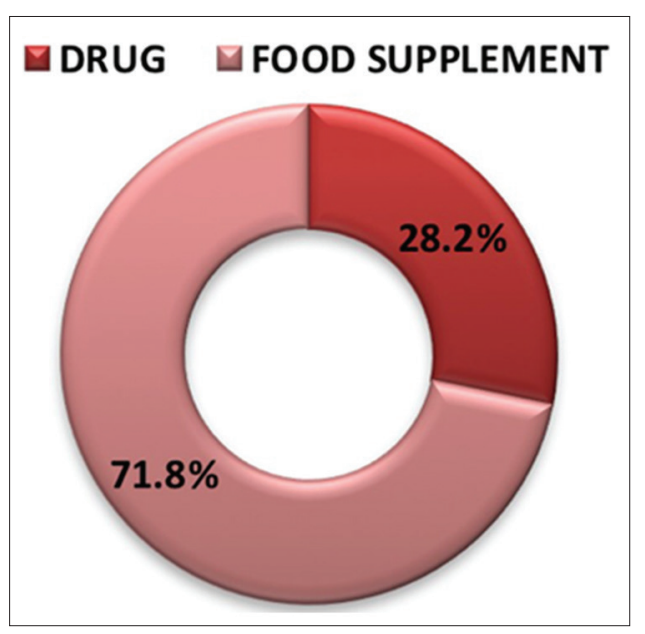

Fig. 5: Caffeine as drug or food supplement

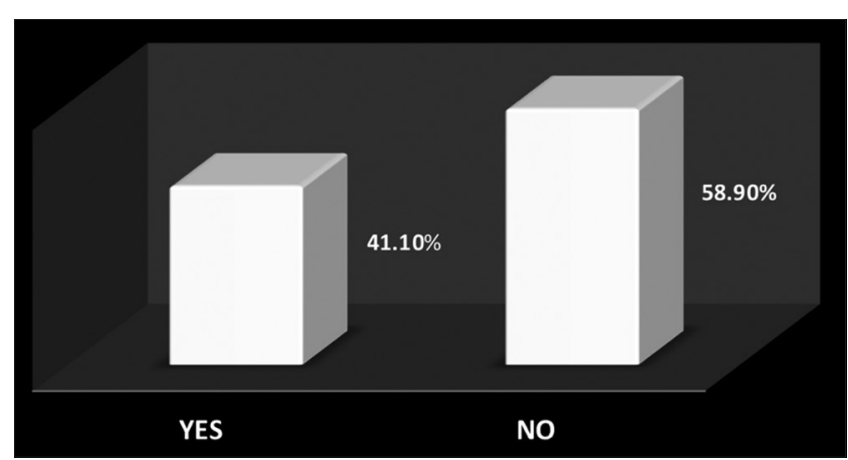

Fig. 6: Caffeine addiction

suggested that caffeine is beneficial in treating asthma and preventing cavities (Brain et al., 2000) [15].

Energy drinks are consumed in relatively high rates among adolescents and adults, with different social and socio-economic factors affecting the consumption of such drinks, along with a partial lack of the scientific sound knowledge concerned with the composition and health implications of consuming these stimulant drinks. Educational and extensional programs should be designed and implemented at the community level to raise the level of awareness about these drinks and their health effects [17].

Although caffeine does not produce with life-threatening health risks commonly associated with the use of classic drugs of addiction such as cocaine, heroin, and nicotine, some caffeine users report becoming "addicted" to caffeine in the sense that they report an inability to quit or to cut down their caffeine use. More research is needed to determine the applicability of substance dependence criteria to caffeine, the prevalence of the disorder, and the utility and clinical significance of the diagnosis. Furthermore, therapeutic assistance should be made available for those who feel that their caffeine use is problematic and have been unable to quit on their own.

\section{CONCLUSION}

Coffee is the most opted source of caffeine among adolescents in Chennai population and people mostly prefer brand name for buying caffeinated products. Although caffeine is used as a food supplement, excessive consumption of caffeine can cause caffeine dependence which further leads to caffeine intoxication. However, awareness programs on caffeine addiction and caffeine intoxication should be mandatory to educate the people more about the devastating effects of caffeine on human health.

\section{REFERENCES}

1. Griffiths R, Juliano L, Chausmer A. Information About Caffeine Dependence; 2005. Available from: http://www.caffeinedependence. org/caffeine_dependence.html. [Last retrieved on 2005 Mar 25].

2. Nehlig A, Daval JL, Debry G. Caffeine and the central nervous system: Mechanisms of action, biochemical, metabolic and psychostimulant effects. Brain Res Brain Res Rev 1992;17:139-70.

3. Brice CF, Smith AP. Factors associated with caffeine consumption. Int J Food Sci Nutr 2002;53:55-64.

4. Weinberg BA, Bealer BK. The World of Caffeine: The Science and Culture of the World's Most Popular Drug. London and New York: Routledge; 2001. p. 3-4.

5. Hannah M. Suave Molecules of Mocha - Coffee, Chemistry, and Civilization. New Partisan; 2005.

6. McIlvain GE. Caffeine Consumption Patterns and Beliefs of College Freshmen. University of Kentucky Doctoral Dissertations. Paper 638; 2008.

7. Story M, Neumark-Sztainer D, French S. Individual and environmental influences on adolescent eating behaviors. J Am Dietc Assoc 2002;102 3 Suppl:40-51.

8. Croll J, Neumark-Sztainer D, Story M. Health eating: What does it mean to adolescents. J Nutr Educ 2001;33(4):193-8.

9. Katholi M, Sstormer E, Stericker P, Rankin C, Katholi C, Katholi R. Zero caffeine for kids. Addiction 2003;98:536-7.

10. Burchfield G. In: Hopes M, editor. What's Your Poison: Caffeine. Australian Broadcasting Corporation; 1997.

11. Kuchment A. Make that a Double: Our Desire for Caffeinated Energy Products is Soaring; 2007. Available from: http:/www.msnbc.msn.com/ $\mathrm{id} / 19875412 /$ site/newsweek/page/0/. [Last retrieved on 2007 Oct 10].

12. Brice CF, Smith AP. Effects of caffeine on mood and performance: A study of realistic consumption. Psychopharmacology (Berl) 2002;164:188-92.

13. Reid TR. (n.d.). Caffeine-what's the buzz? National Geographic. Available from: http://www.science.nationalgeographic.com/science/ health-and-human-body/human- body/caffeine-buzz/.

14. Olsen NL. Caffeine Consumption Habits and Perceptions among University of New Hampshire Students. Honors Theses. Paper $103 ; 2013$.

15. Brain M, Bryant C, Cunningham M. How Caffeine Works; 2000. Available from: http:/www.science.howstuffworks.com/caffeine1.htm.

16. Aubrey A. Young Adults Swapping Soda for the Super Buzz of Coffee [Web Series Episode]. In: The Salt. NPR. Writer; 2013. Available from: http:/www.npr.org/blogs/thesalt/2013/01/14/169161207/young-adultsswapping-soda- for-the-super-buzz-of-coffee.

17. Faris MA. Patterns of caffeinated energy drinks consumption among adolescents and adults in hail, Saudi Arabia. Food Nutr Sci 2014;5(2):158-68. 